\title{
PEGylated Magnetic Nano-Assemblies as Contrast Agents for Effective T2-Weighted MR Imaging
}

\author{
Byunghoon Kang ${ }^{1}$, Jaewoo Lim ${ }^{2,3}$, Hye-young Son ${ }^{4,5}$, Yuna Choi ${ }^{4}$, Taejoon Kang ${ }^{2,3}$ (D), \\ Juyeon Jung ${ }^{2,3}$, Yong-Min Huh ${ }^{4,6, *}$, Seungjoo Haam ${ }^{1, *}$ and Eun-Kyung Lim ${ }^{2,3,6, *(\mathbb{C})}$ \\ 1 Department of Chemical and Biomolecular Engineering, Yonsei University, Seoul 03722, Korea; \\ vv345vv345@naver.com \\ 2 BioNanotechnology Research Center, Korea Research Institute of Bioscience and Biotechnology (KRIBB), \\ 125 Gwahak-ro, Yuseong-gu, Daejeon 34141, Korea; zeuyim5052@kribb.re.kr (J.L.); \\ kangtaejoon@kribb.re.kr (T.K.); jjung@kribb.re.kr (J.J.) \\ 3 Department of Nanobiotechnology, KRIBB School of Biotechnology, University of Science \& \\ Technology (UST), 125 Gwahak-ro, Yuseong-gu, Daejeon 34113, Korea \\ 4 Department of Radiology, College of Medicine, Yonsei University, Seoul 03722, Korea; \\ shy916@yuhs.ac (H.-Y.S.); YUNA517@yuhs.ac (Y.C.) \\ 5 Severance Biomedical Science Institute, College of Medicine, Yonsei University, Seoul 03722, Korea \\ 6 YUHS-KRIBB Medical Convergence Research Institute, Seoul 03722, Korea \\ * Correspondence: ymhuh@yuhs.ac (Y.-M.H.); haam@yonsei.ac.kr (S.H.); eklim1112@kribb.re.kr (E.-K.L.); \\ Tel.: +82-42-879-8456 (E.-K.L.); Fax: +82-42-879-8492 (E.-K.L.)
}

Received: 7 February 2019; Accepted: 6 March 2019; Published: 11 March 2019

\begin{abstract}
We designed a high-sensitivity magnetic resonance imaging contrast agent that could be used to diagnose diseases. First, magnetic nanocrystals were synthesized by a thermal decomposition method on an organic solvent to obtain a high magnetism and methoxy poly(ethylene glycol)-poly(lactic acid) as an amphiphilic polymer using the ring-opening polymerization method to stably disperse the magnetic nanocrystals in an aqueous phase. Subsequently, the magnetic nanoclusters simultaneously self-assembled with methoxy poly(ethylene glycol)-poly(lactic acid) using the nano-emulsion method to form magnetic nanoclusters. Because their shape was similar to a raspberry, they were named PEGylated magnetic nano-assemblies. The PEGylated magnetic nano-assemblies were dispersed stably in the aqueous phase with a uniform size of approximately $65-70 \mathrm{~nm}$ for an extended period ( 0 days: $68.8 \pm 5.1 \mathrm{~nm}$, 33 days: $69.2 \pm 2.0 \mathrm{~nm}$, and 44 days: $63.2 \pm 5.6)$. They exhibited both enough of a magnetic resonance (MR) contrast effect and biocompatibility. In an in vivo study, the PEGylated magnetic nano-assemblies provided a high contrast effect for magnetic resonance images for a long time after one treatment, thereby improving the diagnostic visibility of the disease site.
\end{abstract}

Keywords: Magnetic resonance image; PEGylated; Poly(ethylene glycol)-poly(lactic acid); contrast agent

\section{Introduction}

Magnetic resonance (MR) imaging is the best investigative tool to obtain tomographic images with a high resolution and to offer excellent anatomical information in living organisms. Its detection capability can be greatly enhanced using MR contrast agents that enable noninvasive monitoring and disease identification [1-17]. Magnetic nanocrystals synthesized in an organic phase have well-defined crystallized structures and a high magnetic sensitivity, and they have been reported to be used as contrast agents $[4,18,19]$. Of course, since they are dispersed in the organic phase, additional surface modification with a hydrophilic layer (e.g., polyethylene glycol (PEG)) is required to improve their colloidal stability in the aqueous phase $[7,9,10,12,20-22]$. PEG has a high hydrophilicity, a low cytotoxicity, as well as a high cell permeability; in particular, it contributes to diminishing 
nonspecific interactions with serum proteins by forming hydrogen bonds with water molecules, leading to an increasing residence (circulation) time in the blood [12,15,23-39]. Two main surface modification methods are used for PEG-based materials: (1) the exchange method, in which the hydrophobic ligand on the magnetic nanocrystal (MNC) surface is exchanged with PEG at a high temperature, and (2) the addition method, in which the surface of a hydrophobic MNC is wrapped (or coated or covered) with the emulsion method using a PEG-based amphiphilic polymer as a surfactant $[23-25,27,31-38,40-42]$. This addition method enables the fabrication of a multifunctional nanocomposite by simultaneously loading drugs and fluorescent materials as well as MNCs. However, obtaining uniformly sized nanoparticles, especially nanoclusters, is not easy. There is a limitation in increasing the size of MNCs to enhance the saturation magnetization (Ms) because it also induces the transition between the supermagnetic-ferrimagnetic transitions. Instead, it has been reported that a method of maintaining the superparamagnetic behaviour with a high magnetization by forming magnetic nanoclusters (or assemblies) is effective. Magnetic nanoparticles composed of multiple single MNCs are particularly attractive due to their high magnetic susceptibility, low coercive force, and high magnetic properties $[4,43,44]$.

Herein, we have developed high-sensitivity MRI contrast agents that improve the diagnostic visibility of the disease site. We synthesized mPEG-PLA as a surfactant and then wrapped (encapsulated) hydrophobic 12-nm MNCs with mPEG-PLA using the nano-emulsion method. The particles are formed by homogeneously aggregating MNCs that are dispersed stably in a water phase and are named PEGylate magnetic nano-assemblies (PEGylated MNs).

\section{Materials and Methods}

\subsection{Materials}

Methoxy polyethylene glycol (mPEG) (5 kDa), stannous octoate $\left(\mathrm{Sn}(\mathrm{Oct})_{2}\right), 3,6$-dimethyl-1,4dioxane-2,5-dione (lactide; LA), chloroform, iron (III) acetylacteonate (Fe(acac) 3 ), manganese (II) acetylacetonate $\left(\mathrm{Mn}(\mathrm{acac})_{2}\right), 1,2$-hexadexanediol, lauric acid, laurylamine, and benzyl ether were purchased from Sigma-Aldrich (St. Louis, MO, USA). All other chemicals and reagents were of analytical grade. The cell proliferation kit I (MTT) was purchased from Roche (Basel, Switzerland).

\subsection{Synthesis of Magnetic Nanocrystals (MNCs)}

As previously described, we synthesized hydrophobic magnetic nanocrystals (MNCs and $\left.\mathrm{MnFe}_{2} \mathrm{O}_{4}\right)$ in an organic solvent using the thermal decomposition method [4,7,9,10,12,18-22]; 2 mmol of $\mathrm{Fe}(\mathrm{acac})_{3}, 1 \mathrm{mmol}$ of $\mathrm{Mn}(\mathrm{acac})_{2}, 10 \mathrm{mmol}$ of 1,2-hexadecanediol, $6 \mathrm{mmol}$ of lauric acid, and $6 \mathrm{mmol}$ of laurylamine were dissolved in benzyl ether $(20 \mathrm{~mL})$ under an ambient nitrogen atmosphere. This mixture was preheated to $200{ }^{\circ} \mathrm{C}$ for $2 \mathrm{~h}$ under uniform stirring and then refluxed at $300^{\circ} \mathrm{C}$ for $1 \mathrm{~h}$. After completion of this reaction, the reactants were cooled down to room temperature and purified with an excess of ethyl alcohol (99.9\%) for the products. The MNCs of about $12 \mathrm{~nm}$ were obtained using the seed-mediated growth method.

\subsection{Synthesis of mPEG-PLA by Ring-Opening Polymerization}

The methoxy poly(ethylene glycol)-poly(lactic acid) (mPEG-PLA) as amphiphilic polymers were synthesized by the ring opening polymerization (ROP) method, which the polymerized lactide monomers in the presence of mPEG and $\mathrm{Sn}(\mathrm{Oct})_{2}$ were the catalyst through the use of the bulk method. Briefly, dried mPEG $(2 \mathrm{~g}, 0.4 \mu \mathrm{mol})$, lactide $(0.8 \mathrm{~g}, 5.55 \mu \mathrm{mol})$, and $\mathrm{Sn}(\mathrm{Oct})_{2}(100 \mu \mathrm{L})$ were completely dissolved in $50 \mathrm{~mL}$ of toluene at $120{ }^{\circ} \mathrm{C}$ under a nitrogen atmosphere. After completely melting for $2 \mathrm{~h}$, the mixture was slowly heated to $180^{\circ} \mathrm{C}$ for $4 \mathrm{~h}$. After the reaction was terminated, the heat source was removed from the reactant and the temperature was cooled down to room temperature. The solvent of this reactant was rapidly eliminated using a rotary evaporator $(50 \mathrm{HZ}$, EYELA). For purification, this reactant was redissolved in toluene $(2 \mathrm{~mL})$ and precipitated in excess 
cold diethyl ether, and then, it was filtered using a vacuum filtration. This purification process was repeated three times. The reactant was freeze-dried to obtain a purified product as a white powder and stored under a vacuum before use. The synthesized mPEG-PLA was analyzed using FTIR and ${ }^{1} \mathrm{H}-\mathrm{NMR}$ spectroscopy with $\mathrm{CDCl}_{3}$. The critical micelle concentration (CMC) of mPEG-PLA was measured by conductivity. The conductivity $\left(\mu \mathrm{S} \mathrm{cm}{ }^{-1}\right)$ of the mPEG-PLA solutions with various concentrations was measured using a conductivity meter. The mPEG-PLA concentration was plotted against the conductivity. The CMC was identified as the point on a plot where the slope changes.

\subsection{Preparation of PEGylated Magnetic Nano-Assemblies (PEGylated MNs)}

The PEGylated MNs were prepared by a nano-emulsion method. The mPEG-PLA solution and MNC-containing organic phase were prepared by dissolving mPEG-PLA $(100 \mathrm{mg})$ and MNC $(20 \mathrm{mg})$ in deionized water $(20 \mathrm{~mL})$ and methylene chloride $(4 \mathrm{~mL})$, respectively.

Afterwards, the MNC-containing organic solvent was poured into the mPEG-PLA solution. This solution was ultra-sonicated in an ice bath for $20 \mathrm{~min}$ at $450 \mathrm{rpm}$ and stirred overnight at room temperature to evaporate methylene chloride. The resulting suspension was centrifuged 3 times for $30 \mathrm{~min}$ each at 18,000 rpm. After the supernatant was removed, the precipitated PEGylated MNs was re-dispersed in $5 \mathrm{~mL}$ of DI water. After the preparation, the size distributions and surface charges of the PEGylated MNVs were analyzed by a particle size and zeta-potential analyzer (ELS-Z, Otsuka Electronics). Additionally, its colloidal stability was analyzed by measuring the size variation, monitoring for 44 days. Their morphologies and magnetic properties were analyzed by transmittance electron microscopy (TEM, TECNAI G2, FEI) and a vibrating-sample magnetometer (VSM) at 298K, respectively. The weight ratio (\%) of mPEG-PLA in the samples was measured using thermos-gravimetric analysis. Finally, the relaxivity (R2) data were obtained by using magnetic resonance (MR) imaging analysis.

\subsection{Biocompatibility Tests}

The biocompatibility of mPEG-PLA and PEGylated MNs against NIH3T6.7 cells was evaluated by measuring the inhibition of cell proliferation using the MTT assay kit. The NIH3T6.7 cells were maintained in Dulbecco's modified eagle's medium (DMEM) containing fetal bovine serum (FBS) $(10 \%)$ and antibiotics $(1 \%)$ at $37^{\circ} \mathrm{C}$ in a humidified atmosphere with $5 \% \mathrm{CO}_{2}$. Seeded were $10^{4}$ cells per well into a $96-$-well plate, and they were incubated at $37^{\circ} \mathrm{C}$ overnight to attach onto the wells. Then, they were treated with various concentrations of mPEG-PLA and the PEGylated MN solution and further incubated for $24 \mathrm{~h}$. The MTT assay was performed depending on the procedure recommended by the manual. The cell viability (\%) was determined as the ratio of purple intensity in viable cells treated with mPEG-PLA and PEGylated MNs to the intensity in nontreated (control) cells. The cell viability was normalized to that of the control cells (which were considered to have $100 \%$ cell viability).

\subsection{In Vivo (Mouse Xenograft Tumor) Model Procedure}

We performed mouse xenograft in tumor models, in which NIH3T6.7 cells ( $10^{7}$ cells in $50 \mu \mathrm{L}$ of saline per animal) were implanted in the proximal thigh region of BALB/c-nude mice (4-5 weeks of age) $[7,11,45]$. Then, the MR imaging was performed using 5 mice 4 weeks after the tumor cell transplantation. All animal experiments were conducted with the approval of the Association for Assessment and Accreditation of Laboratory Animal Care (AAALAC) International.

\subsection{MR Imaging Procedure}

We performed the MR imaging experiment of a PEGylated MN solution with a $1.5 \mathrm{~T}$ clinical MRI instrument with a micro47 surface coil (Intera; Philips Medical Systems, Best, the Netherlands). The T2 weights of various concentrations of PEGylated MN solution were measured by the Carr-Purcell-Meiboom-Gill (CPMG) sequence at room temperature with the following parameters: $\mathrm{TR}=10 \mathrm{~s}$, 32 echoes with a 12-ms even echo space, number of acquisitions $=1$, point resolution of 
$156 \times 156 \mathrm{~mm}$, and section thickness of $0.6 \mathrm{~mm}$. The relaxivity coefficient $\left(\mathrm{mM}^{-1} \mathrm{~s}^{-1}\right)$ was equal to the ratio of $\mathrm{R} 2\left(1 / \mathrm{T} 2, \mathrm{~S}^{-1}\right)$ to the PEGylated $\mathrm{MN}$ concentration. In addition, in vivo MR imaging experiments were performed with a $3 \mathrm{~T}$ clinical MRI instrument with a micro-47 surface coil (Intera; Philips Medical Systems, Best, the Netherlands). The T2 weights of a nude mouse injected with PEGylated MNs were measured by the CPMG sequence at room temperature with the following parameters: TR $=10 \mathrm{~s}, 32$ echoes with a 12 -ms even echo space, number of acquisitions $=1$, point resolution of $156 \times 156 \mathrm{~mm}$, and section thickness of $0.6 \mathrm{~mm}$. For the T2-weighted MR imaging of the nude mouse model, we adopted the following parameters: resolution of $234 \times 234 \mathrm{~mm}$, section thickness of $2.0 \mathrm{~mm}, \mathrm{TE}=60 \mathrm{~ms}, \mathrm{TR}=4000 \mathrm{~ms}$, and number of acquisitions $=1$.

\section{Results and Discussion}

\subsection{Synthesis and Characterization of $m P E G-P L A$}

We synthesized mPEG-PLA as an amphiphilic copolymer that could effectively encapsulate hydrophobic magnetic nanocrystals through ring-opening polymerization (Figure 1) [23-25,27,31-38,41]. mPEG(5K)-PLA(2K) was obtained by controlling the feed ratio (LA/EG), and its chemical structure was confirmed using FTIR and an ${ }^{1} \mathrm{H}-\mathrm{NMR}$ spectrometer (Figure 2) [28,33,35-37,43]. The hydroxyl groups at the end of mPEG acted as the initiators, and the lactide monomers for the attachment and growth of the PLA blocks were located at the end of PEG. mPEG-PLA commonly showed an absorption that was assigned to the $\mathrm{C}-\mathrm{O}-\mathrm{C}$ band of $\mathrm{mPEG}\left(1087-1184 \mathrm{~cm}^{-1}\right)$, the $-\mathrm{C}=\mathrm{O}$ stretching of lactide (LA) (1750-1760 $\left.\mathrm{cm}^{-1}\right)$, and the $-\mathrm{CH}_{2}-$ stretching of mPEG $\left(2850-2950 \mathrm{~cm}^{-1}\right)$. However, compared with that of LA, the strong peak at $1150-1300 \mathrm{~cm}^{-1}$ indicated the $\mathrm{C}-\mathrm{C}(=\mathrm{O})-\mathrm{O}$ vibration of LA disappeared (Figure 2a). As shown in Figure $2 b$, the peaks corresponding to the methylene $\left(-\mathrm{CH}_{2}-\right)$ and methoxy end $\left(\mathrm{CH}_{3} \mathrm{O}-\right)$ groups of $\mathrm{mPEG}$ were still confirmed at approximately $3.38 \mathrm{ppm}$ and $3.64 \mathrm{ppm}$, respectively, but the peak corresponding to the hydroxyl $(-\mathrm{OH})$ group was no longer observed at $4.79 \mathrm{ppm}$. Additionally, the methyne $(\mathrm{CH})$ and methyl $\left(-\mathrm{CH}_{3}\right)$ groups were observed in PLA at $5.17 \mathrm{ppm}$ and $1.60 \mathrm{ppm}$, respectively. These spectra indicated that mPEG-PLA was successfully synthesized. We also measured the conductivity of mPEG-PLA to confirm its applicability as an amphiphilic polymer. The conductivity increases almost linearly with the mPEG-PLA concentration; after a certain concentration is reached, the conductivity increases linearly with the lower slope. This concentration at which the slope of conductivity changes was identified as the critical micelle concentration (CMC) (Figure 3) $[39,46]$. This result indicated that the surfactant adsorption at the interface did not increase until the mPEG-PLA concentration reached $5.496 \mu \mathrm{M}$; however, the further addition of mPEG-PLA resulted in the formation of micelles in the solution.

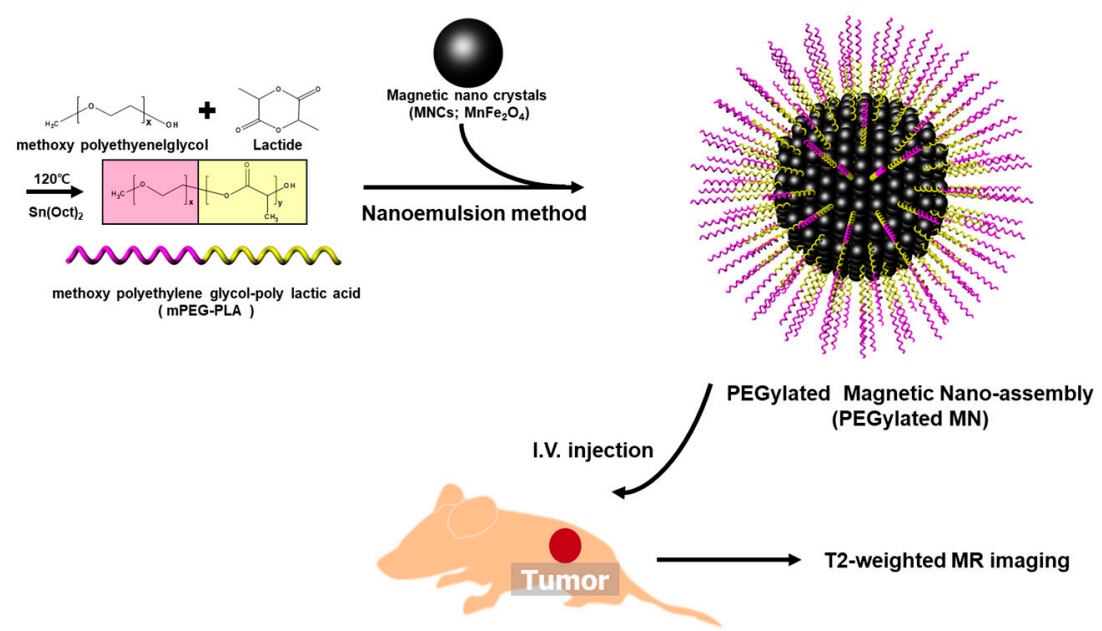

Figure 1. A schematic illustration of PEGylated magnetic nano-assembly (PEGylated MN) synthesis using mPEG-PLA and magnetic nanocrystals $\left(\mathrm{MNC}_{\mathrm{S}}\right)$ as an effective MRI contrast agent. 

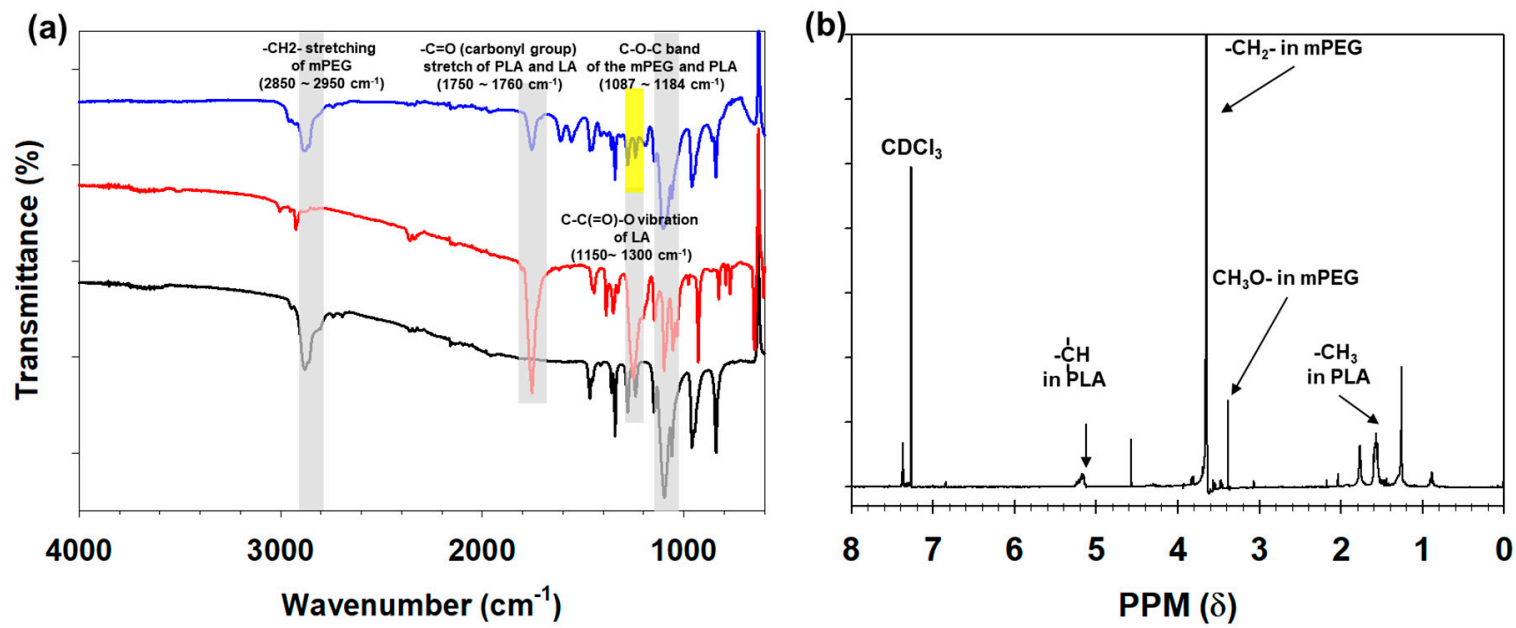

Figure 2. (a) The FTIR spectra of mPEG (5K) (black), lactide (red), and mPEG-PLA (blue) and (b) the ${ }^{1} \mathrm{H}-\mathrm{NMR}$ spectrum of mPEG-PLA ( $\mathrm{CDCl}_{3}$ : Solvent).

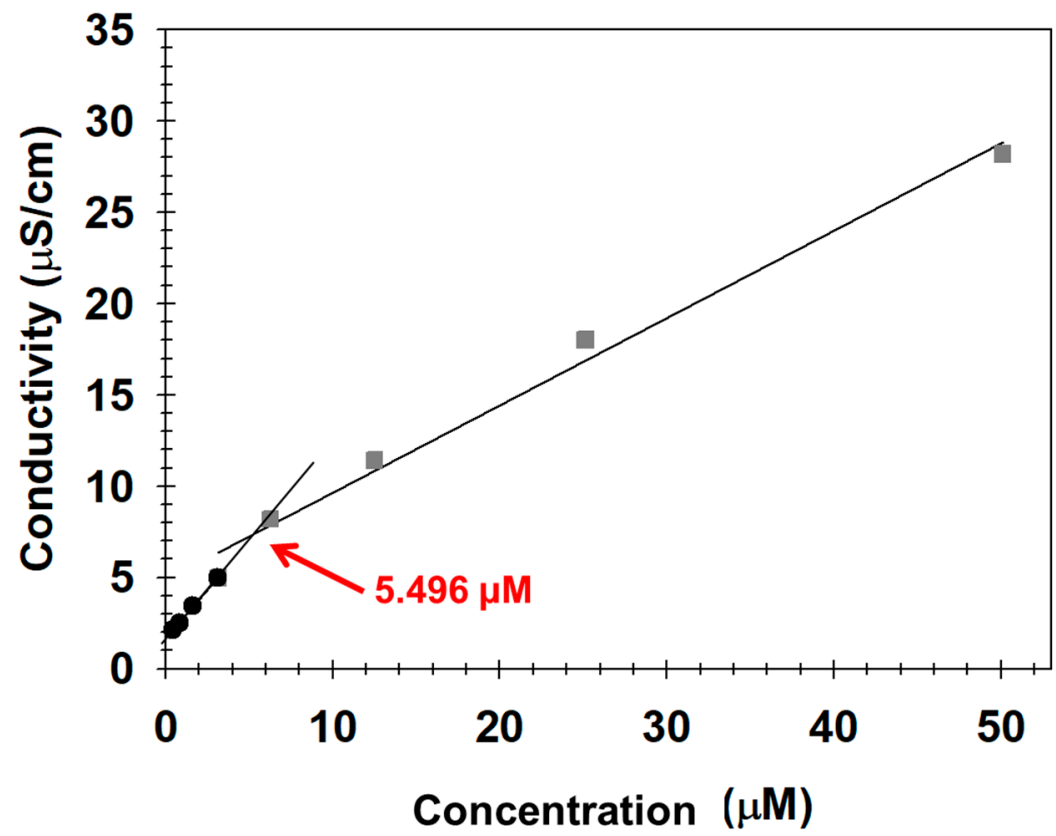

Figure 3. The determination of the critical micelle concentration (CMC) of mPEG-PLA using conductivity.

\subsection{Formulation and Characterization of PEGylated MNs}

We fabricated PEGylated magnetic nanoparticles composed of hydrophobic magnetic nanocrystals (MNCs) encapsulated by mPEG-PLA using the nano-emulsion method [3,7-13,16,20-22,39,45,47,48]. The morphologies of these particles confirmed by TEM showed that MNCs were clustered spherically (Figure 4a). Based on this TEM image, we denoted this nanoparticle as a PEGylated magnetic nanoberry (PEGylated MN). We also observed that their stability changed over time and measured their sizes and surface charges using laser scattering ( 0 day: $68.8 \pm 5.1 \mathrm{~nm}$ and $0.7 \pm 0.3 \mathrm{mV}, 33$ day: $69.2 \pm 2.0 \mathrm{~nm}$ and $-2.4 \pm 0.7 \mathrm{mV}$, and 44 day: $63.2 \pm 5.6 \mathrm{~nm}$ and $-1.1 \pm 0.9 \mathrm{mV}$, respectively). After PEGylated MN fabrication, we visually observed their colloidal stability for 15 day. The day when the particles were produced was referred to as day 0. As shown in Figure 4b, these PEGylated MNs did not agglomerate for a long time (15 days) and remained very stable in the aqueous phase. Additionally, their sizes and charges barely changed over a 44-day period due to the PEGylation effect $[23,26,28-30]$. This finding signifies that the surface of the PEGylated MNs was well-coated with mPEG-PLA. Therefore, these particles could be stably presented in the water phase because of the hydrogen bonding with PEG 
molecules on the surface of PEGylated MNs and water molecules. As well, the poly dispersity index (PDI) values were calculated based on the dynamic light scattering (DLS) analysis results. When each

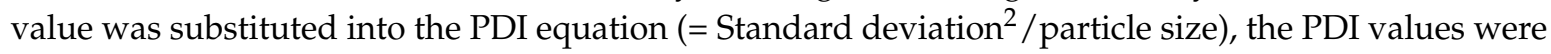
$0.38,0.06$, and 0.49 , respectively (Table 1 and Figure S1). The PDI values of the particles ranged from 0 to 0.0 .8 in the nearly monodispersed and 0.08 to 0.7 in the uniformly dispersed [49]. Based on our PDI values, we judged that PEGylated MN exhibited uniform dispersion and was acceptable to use in the pharmaceutical filed.

Table 1. The size, poly dispersity index (PDI) values, and zeta potential data of PEGylated MN over 44 days.

\begin{tabular}{cccc}
\hline Time & Size $(\mathbf{n m})$ & PDI $^{\mathbf{a}}$ & Zeta $(\mathbf{m V})$ \\
\hline 0 day & $68.8 \pm 5.1$ & 0.38 & $0.7 \pm 0.3$ \\
33 days & $69.2 \pm 2.0$ & 0.06 & $-2.4 \pm 0.7$ \\
44 days & $63.2 \pm 5.6$ & 0.49 & $-1.1 \pm 0.9$ \\
\hline
\end{tabular}

All data are depicted as the mean \pm S.D, and $\mathrm{N}>3,{ }^{a} \mathrm{PDI}=(\text { S.D. })^{2} /$ Avg. size.
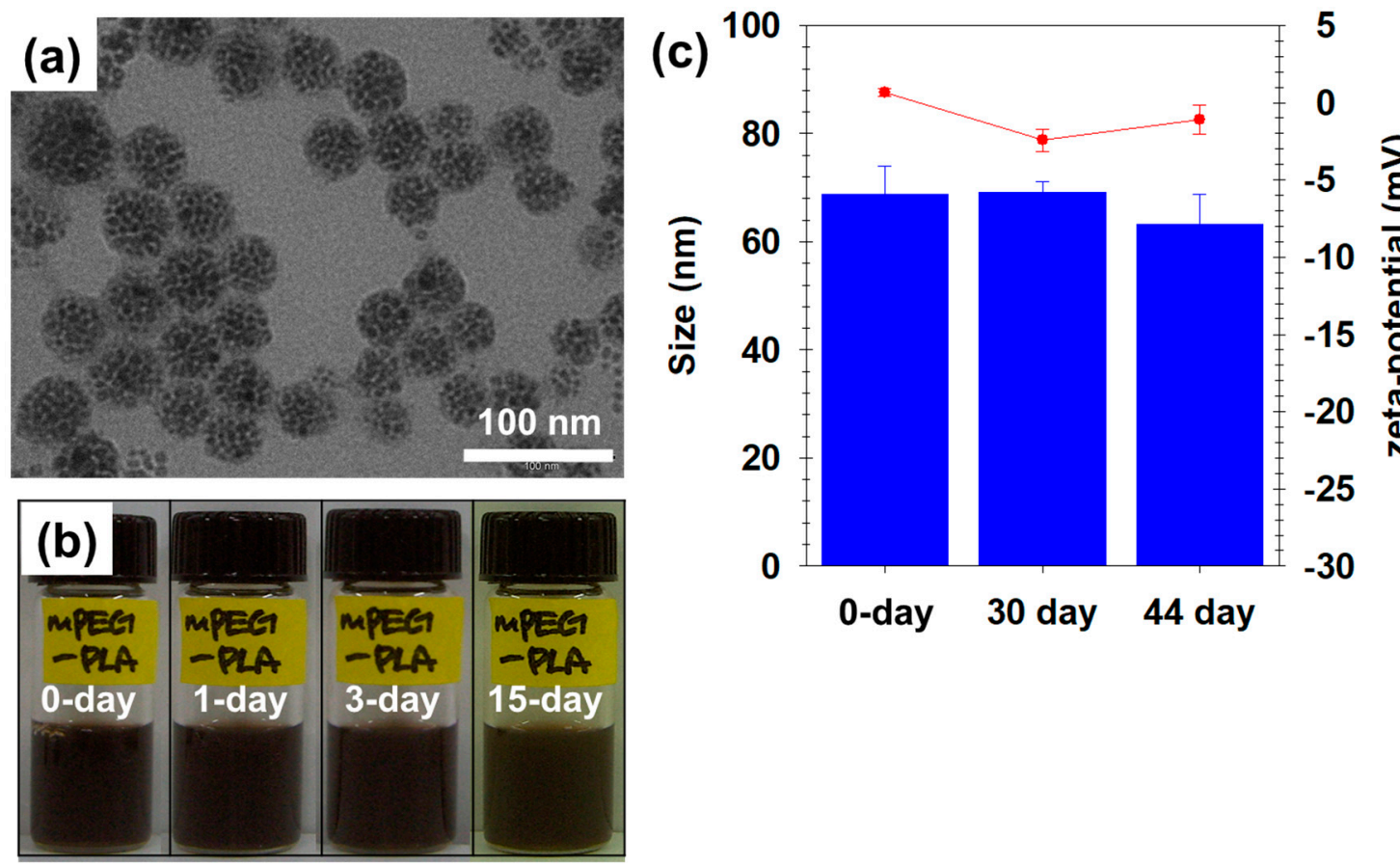

Figure 4. (a) The transmission electron microscopy (TEM) images of PEGylated MNs, (b) their colloidal stability for 15 days, and (c) their size distribution (blue bars) and zeta-potential (red circles) analyses over 44 days.

The weight (\%) of the MNCs in PEGylated MNs was analyzed by a thermogravimetric analysis as the obtained amount of MNCs divided by the initial amount of PEGylated MNs. It was confirmed that the magnetic sensitivity of MNCs was affected by their size and composition [44,46]. Of the 4 types pf MNCs $\left(\mathrm{MnFe}_{2} \mathrm{O}_{4}, \mathrm{Fe}_{3} \mathrm{O}_{4}, \mathrm{CoFe}_{2} \mathrm{O}_{4}\right.$, and $\left.\mathrm{NiFe}_{2} \mathrm{O}_{4}\right), \mathrm{MnFe}_{2} \mathrm{O} 4$ nanocrystals showed the strongest MR contrast effect, with high relaxivity values. Especially, 12-nm $\mathrm{MnFe}_{2} \mathrm{O}_{4}$ nanocrystals exhibited the highest mass magnetization value. Based on this previous references, we used 12-nm $\mathrm{MnFe}_{2} \mathrm{O}_{4}$ nanocrystals as MNCs to fabricate PEGylated MNs. A total of $81.3 \mathrm{wt} \%$ of MNCs was loaded into the PEGylated MNs (Figure 5a). Despite the $18.7 \mathrm{wt} \% \mathrm{mPEG}-\mathrm{PLA}$ coating, the superparamagnetism of 12-nm MNCs was maintained with a high saturated magnetization value (40.3 emu/gMNCs) at $298 \mathrm{~K}$ (Figure 5b) [4,43]. These results demonstrated that PEGylated MNs well-covered with mPEG-PLA exhibited high magnetic properties. 

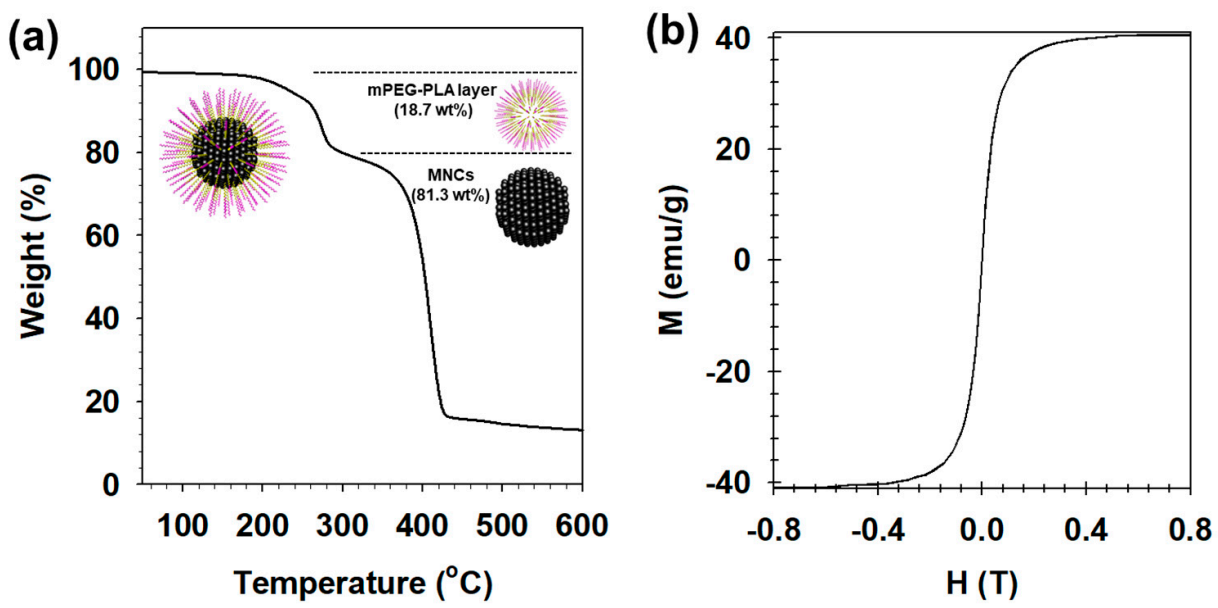

Figure 5. (a) The magnetic hysteresis loops and (b) thermogravimetric analysis (TGA) of the PEGylated MNs.

We evaluated the feasibility of PEGylated MNs as MR imaging agents and measured their MR signal intensities in an aqueous phase under various concentrations at room temperature. In Figure 6, the T2-weighted MR image showed an increasingly stronger black as the concentration increased, and their T2 values were measured. The relaxivity (r2) of PEGylated MNs was calculated from the least-square curve fitting of the MNC concentration versus relaxation rate $\left(R 2, S^{-1}\right)$. The corresponding r2 coefficient was determined to be $217.07 \mathrm{mM}^{-1} \mathrm{~s}^{-1}$, that was higher (approximately 1.13-fold) than that of commercial MRI contrast media (Ferumoxide: $190.5 \mathrm{mM}^{-1} \mathrm{~s}^{-1}$ ) [46,50]. These findings demonstrated that PEGylated MNs possessed a remarkably high MR imaging effect due to the enhanced magnetism through the dense clustering of a large amount of 12-nm $\mathrm{MnFe}_{2} \mathrm{O}_{4}(\mathrm{MNCs})$ in the PEGylated MNs $[4,43,44]$.
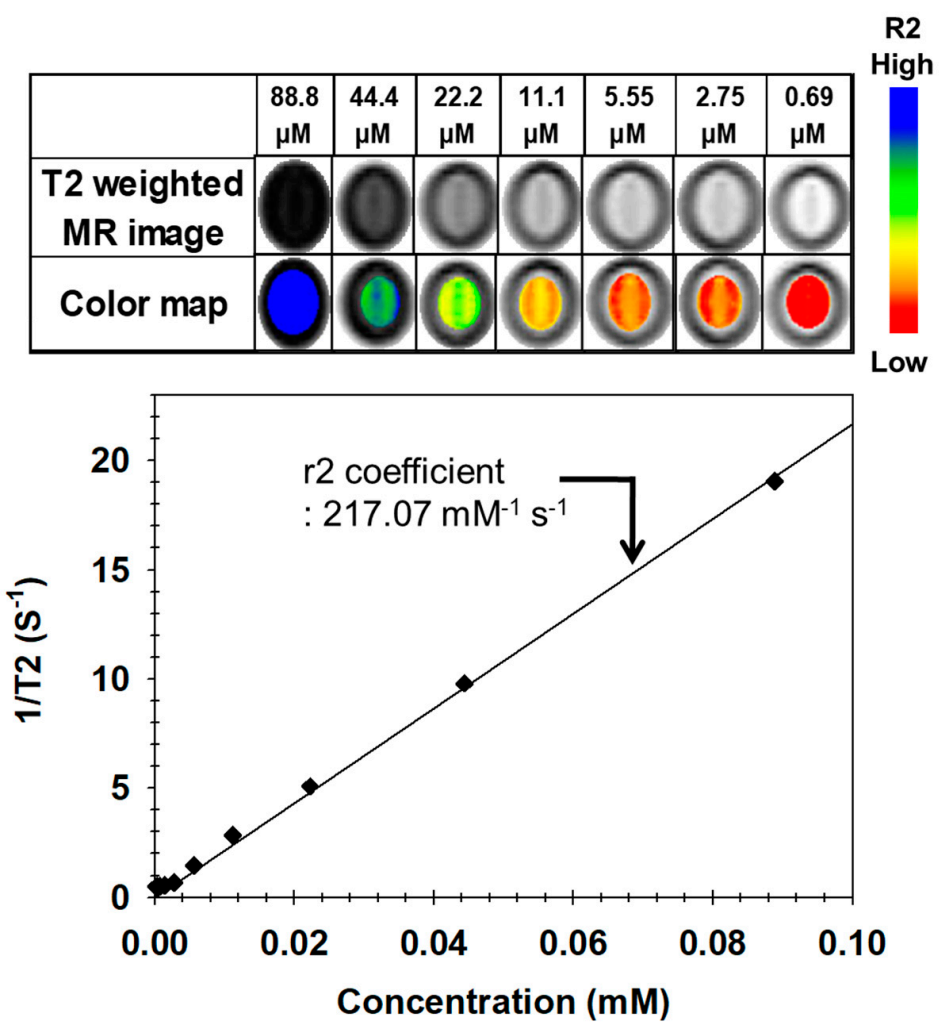

Figure 6. The T2-weighted MR images of a PEGylated MN solution and their color maps and their $1 / \mathrm{T} 2\left(\mathrm{~S}^{-1}\right)$ values at $1.5 \mathrm{~T}$. 


\subsection{Biocompatibility of the PEGylated MNs}

Before applying the particles for in vivo imaging, first we evaluated the biocompatibility of the PEGylated MNs against NIH3T6.7 cells using a MTT assay that was performed after incubation with various concentrations overnight. The cell viability was maintained above $80 \%$ without inhibitory effects on the cell proliferation within the PEGylated $\mathrm{MN}$ concentration range. Even when inorganic MNCs were present in them, no effect on the cell viability was observed compared to that of mPEG-PLA (Figure 7) $[23,27,31-37,41,42]$.

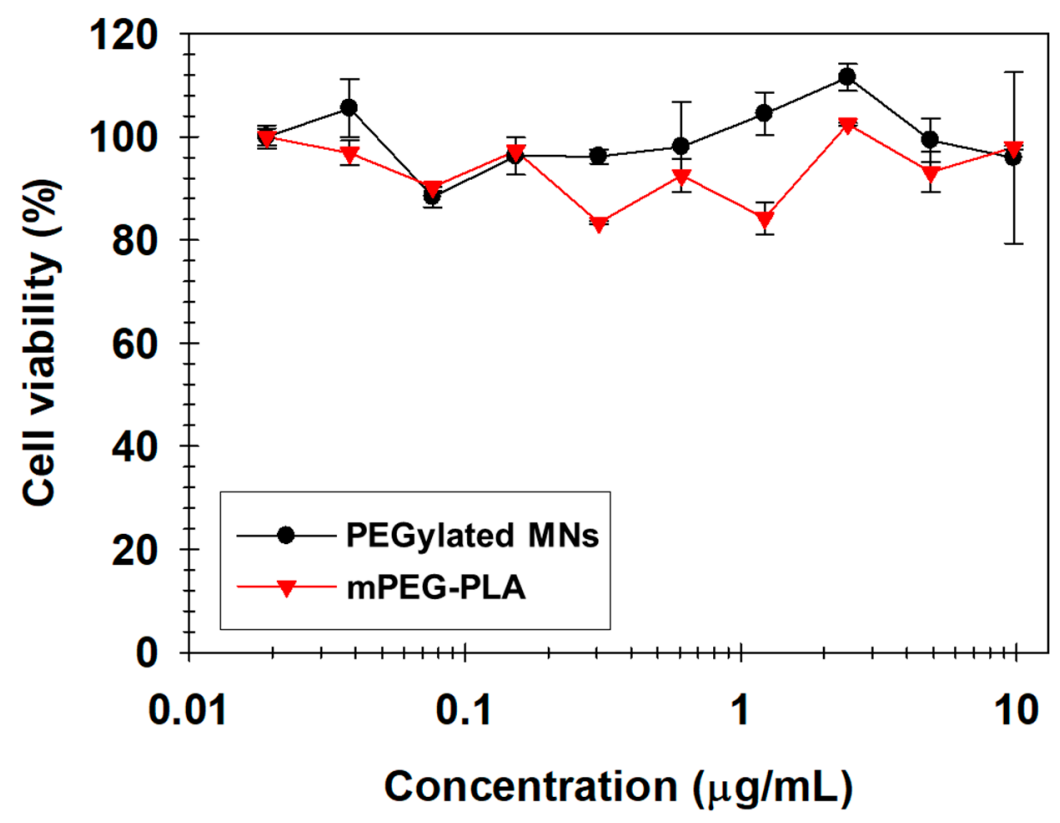

Figure 7. The viability of cells treated with mPEG-PLA $(\mathbf{\nabla})$ and PEGylated MN $(\bullet)$ at various concentrations.

\subsection{In Vivo MR Imaging}

Next, we performed MR imaging in mouse xenograft tumor models using PEGylated MNs to evaluate their diagnostic ability as MR imaging contrast agents. First, BALB/c-nude mice were subcutaneously implanted in the proximal thigh with NIH3T6.7 cells for the xenograft mouse model, and PEGylated MNs (200 $\mu \mathrm{g}_{\mathrm{Fe}+\mathrm{Mn}}$ in $200 \mu \mathrm{L}$ buffer) were injected into the tail vein of the mouse (intravenous injection). After a PEGylated MN injection, we observed that the tumor region became gradually darker along the intra-tumoral blood vessels with a high MR signal intensity (Figure 8a). In particular, the MR signal at the tumor region was consistently enhanced with darkening on the MR image by increasing the $\Delta \mathrm{R} 2 / \mathrm{R} 2$ Pre value by about $16.0 \%$ at $7 \mathrm{~h}$ postinjection relative to the preinjection intensity (Figure 8c). Additionally, we clearly identified the MR signal changes by color-mapping the tumor areas of the MR image. The color map image was intended to make the R2 value (MR signal) change value visually clear. In a color map image, as the MR signal increases, the color changes from blue to red. Therefore, in Figure $8 \mathrm{~b}$, the red color spread out gradually along the vascular distribution as the MR signal increased, similar to the T2-weighted MR images. These results indicated that PEGylated MNs were capable of sufficiently long-term circulation in the bloodstream (body) due to their physical properties (e.g., PEGylation), thereby enabling the accumulation in tumor tissues by the enhanced permeability and retention (EPR) effect. 


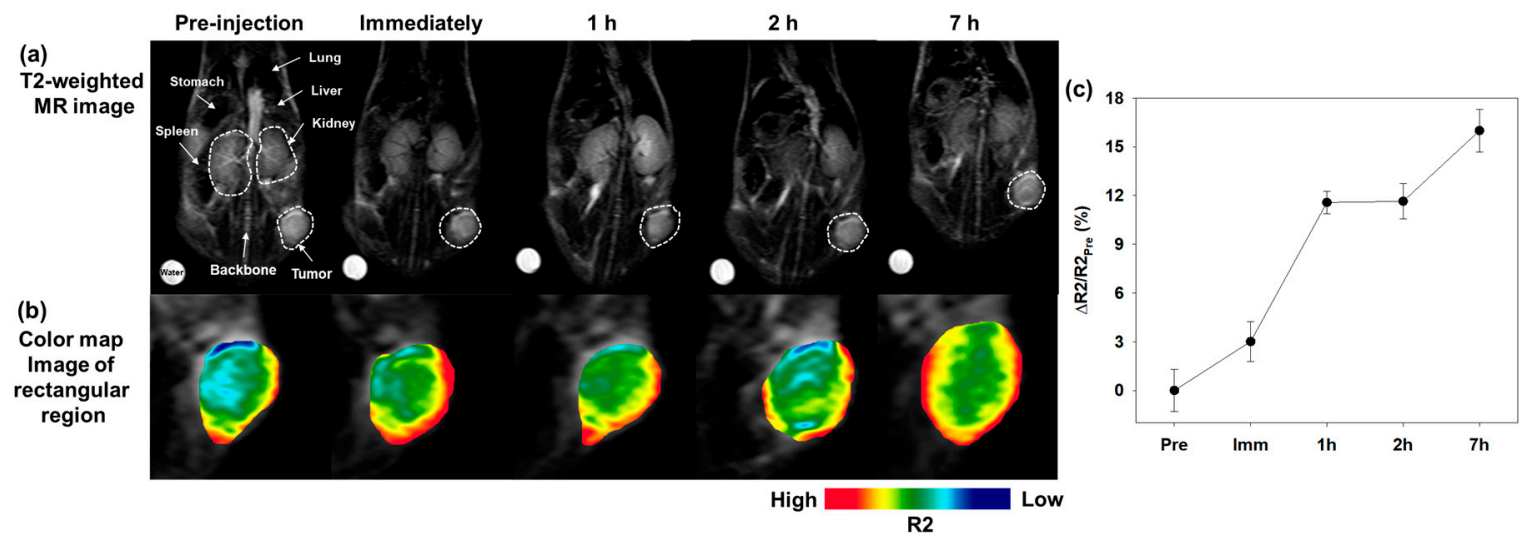

Figure 8. (a) The T2-weighted MR images of mice and (b) the color-map images of the polygonal region with the white dashed line of Figure $8 \mathrm{a}$. (c) The $\Delta \mathrm{R} 2 / \mathrm{R} 2 \mathrm{Pre}$ (\%) graph of the T2-weighted MR images versus the time after an intravenous venous (I.V.) injection of PEGylated MNs (Pre: preinjection, IMM: immediately following the injection, $1 \mathrm{~h}: 1 \mathrm{~h}$ following the injection, $3 \mathrm{~h}: 3 \mathrm{~h}$ following the injection, and $7 \mathrm{~h}$ : $7 \mathrm{~h}$ following the injection). A $3.0 \mathrm{~T}$ human MR scanner was used.

\section{Conclusions}

In this study, we synthesized mPEG-PLA as an amphiphilic polymer using the ring-opening polymerization method and then encapsulated the hydrophobic magnetic nanocrystals (MNCs) in an organic solvent with mPEG-PLA using the nano-emulsion method to allow the stable dispersion in the aqueous phase. At this time, the MNCs were uniformly assembled in raspberry form, and we named it PEGylated magnetic nano-assemblies (PEGylated MNs). The PEGylated MNs exhibited a good stability in an aqueous phase for an extended time due to the PEG molecules on the particle surface (PEGylation effect) as well as an enough of an MR contrast effect due to the magnetic clustering effect compared to those of a commercial MR contrast agent. In addition, we confirmed that PEGylated MNs had a potential use as MRI agents for cancer detection through in vivo studies.

Supplementary Materials: The following are available online at http:/ /www.mdpi.com/2079-4991/9/3/410/s1. Figure S1: The size analysis graphs of PEGylated MNs over 44 days (a): 0 day, (b): 30 day and (c): 44 day. All measurements were repeated three times.

Author Contributions: E.-K.L., S.H., and Y.-M.H. conceived and designed the experiments; B.K., Y.C., and H.-Y.S. performed the experiments; H.-Y.S. and Y.-M.H. analyzed the data; T.K. and J.J. contributed the reagents/materials/analysis tools.

Funding: This work was supported by the Center for BioNano HealthGuard funded by the Ministry of Science and ICT (MSIT) as Global Frontier Project (H-GUARD_2014M3A6B2060507 and HGUARD_2013M3A6B2078950), the Bio \& Medical Technology Development Program of the National Research Foundation (NRF) funded by MSIT (NRF-2018M3A9E2022821), the Basic Science Research Program of the NRF funded by MSIT (NRF2018R1C1B6005424 and NRF-2019R1C1C1006867), and KRIBB Research Initiative Program.

Conflicts of Interest: The authors declare no conflict of interest.

\section{References}

1. Arami, H.; Khandhar, A.P.; Tomitaka, A.; Yu, E.; Goodwill, P.W.; Conolly, S.M.; Krishnan, K.M. In vivo multimodal magnetic particle imaging (MPI) with tailored magneto/optical contrast agents. Biomaterials 2015, 52, 251-261. [CrossRef] [PubMed]

2. Fang, C.; Zhang, M. Multifunctional magnetic nanoparticles for medical imaging applications. J. Mater. Chem. 2009, 19, 6258-6266. [CrossRef] [PubMed]

3. Kim, M.H.; Kim, B.; Lim, E.K.; Choi, Y.; Choi, J.; Kim, E.; Jang, E.; Park, H.S.; Suh, J.S.; Huh, Y.M.; et al. Magnetic nanoclusters engineered by polymer-controlled self-assembly for the accurate diagnosis of atherosclerotic plaques via magnetic resonance imaging. Macromol. Biosci. 2014, 14, 943-952. [CrossRef] [PubMed] 
4. Lee, J.H.; Huh, Y.M.; Jun, Y.W.; Seo, J.W.; Jang, J.T.; Song, H.T.; Kim, S.; Cho, E.J.; Yoon, H.G.; Suh, J.S.; et al. Artificially engineered magnetic nanoparticles for ultra-sensitive molecular imaging. Nat. Med. 2007, 13, 95-99. [CrossRef] [PubMed]

5. Lee, S.-J.; Jeong, J.-R.; Shin, S.-C.; Kim, J.-C.; Chang, Y.-H.; Chang, Y.-M.; Kim, J.-D. Nanoparticles of magnetic ferric oxides encapsulated with poly(D,L latide-co-glycolide) and their applications to magnetic resonance imaging contrast agent. J. Magn. Magn. Mater. 2004, 272-276, 2432-2433. [CrossRef]

6. Li, Z.; Yin, S.; Cheng, L.; Yang, K.; Li, Y.; Liu, Z. Magnetic targeting enhanced theranostic strategy based on multimodal imaging for selective ablation of cancer. Adv. Funct. Mater. 2014, 24, 2312-2321. [CrossRef]

7. Lim, E.K.; Huh, Y.M.; Yang, J.; Lee, K.; Suh, J.S.; Haam, S. pH-triggered drug-releasing magnetic nanoparticles for cancer therapy guided by molecular imaging by MRI. Adv. Mater. 2011, 23, 2436-2442. [CrossRef] [PubMed]

8. Lim, E.K.; Kang, B.; Choi, Y.; Jang, E.; Han, S.; Lee, K.; Suh, J.S.; Haam, S.; Huh, Y.M. Gadolinium-based nanoparticles for highly efficient T1-weighted magnetic resonance imaging. Nanotechnology 2014, 25, 245103-245112. [CrossRef] [PubMed]

9. Lim, E.K.; Kim, B.; Choi, Y.; Ro, Y.; Cho, E.J.; Lee, J.H.; Ryu, S.H.; Suh, J.S.; Haam, S.; Huh, Y.M. Aptamer-conjugated magnetic nanoparticles enable efficient targeted detection of integrin alphavbeta3 via magnetic resonance imaging. J. Biomed. Mater. Res. A 2014, 102, 49-59. [CrossRef] [PubMed]

10. Lim, E.K.; Kim, H.O.; Jang, E.; Park, J.; Lee, K.; Suh, J.S.; Huh, Y.M.; Haam, S. Hyaluronan-modified magnetic nanoclusters for detection of CD44-overexpressing breast cancer by MR imaging. Biomaterials 2011, 32, 7941-7950. [CrossRef] [PubMed]

11. Lim, E.K.; Yang, J.; Dinney, C.P.; Suh, J.S.; Huh, Y.M.; Haam, S. Self-assembled fluorescent magnetic nanoprobes for multimode-biomedical imaging. Biomaterials 2010, 31, 9310-9319. [CrossRef] [PubMed]

12. Lim, E.K.; Yang, J.; Park, M.Y.; Park, J.; Suh, J.S.; Yoon, H.G.; Huh, Y.M.; Haam, S. Synthesis of water soluble PEGylated magnetic complexes using mPEG-fatty acid for biomedical applications. Colloids Surf. B Biointerfaces 2008, 64, 111-117. [CrossRef] [PubMed]

13. Lim, E.-K.; Jang, E.; Kim, B.; Choi, J.; Lee, K.; Suh, J.-S.; Huh, Y.-M.; Haam, S. Dextran-coated magnetic nanoclusters as highly sensitive contrast agents for magnetic resonance imaging of inflammatory macrophages. J. Mater. Chem. 2011, 21, 12473-12478. [CrossRef]

14. Veiseh, O.; Gunn, J.W.; Zhang, M. Design and fabrication of magnetic nanoparticles for targeted drug delivery and imaging. Adv. Drug Deliv. Rev. 2010, 62, 284-304. [CrossRef] [PubMed]

15. Wuang, S.C.; Neoh, K.G.; Kang, E.T.; Pack, D.W.; Leckband, D.E. HER-2-mediated endocytosis of magnetic nanospheres and the implications in cell targeting and particle magnetization. Biomaterials 2008, 29, 2270-2279. [CrossRef] [PubMed]

16. Yang, J.; Lim, E.K.; Lee, H.J.; Park, J.; Lee, S.C.; Lee, K.; Yoon, H.G.; Suh, J.S.; Huh, Y.M.; Haam, S. Fluorescent magnetic nanohybrids as multimodal imaging agents for human epithelial cancer detection. Biomaterials 2008, 29, 2548-2555. [CrossRef] [PubMed]

17. Yang, S.H.; Heo, D.; Lee, E.; Kim, E.; Lim, E.K.; Lee, Y.H.; Haam, S.; Suh, J.S.; Huh, Y.M.; Yang, J.; et al. Galactosylated manganese ferrite nanoparticles for targeted MR imaging of asialoglycoprotein receptor. Nanotechnology 2013, 24, 475103. [CrossRef] [PubMed]

18. Kwon, S.G.; Piao, Y.; Park, J.; Angappane, S.; Jo, Y.; Hwang, N.-M.; Park, J.-G.; Hyeon, T. Kinetics of monodisperse iron oxide nanocrystal formation by "heating-up" process. J. Am. Chem. Soc. 2007, 129, 12571-12584. [CrossRef] [PubMed]

19. Park, J.; Joo, J.; Kwon, S.G.; Jang, Y.; Hyeon, T. Synthesis of monodisperse spherical nanocrystals. Angew. Chem. Int. Ed. Engl. 2007, 46, 4630-4660. [CrossRef] [PubMed]

20. Lim, E.K.; Chung, B.H. Preparation of pyrenyl-based multifunctional nanocomposites for biomedical applications. Nat. Protoc. 2016, 11, 236-251. [CrossRef] [PubMed]

21. Lim, E.-K.; Sajomsang, W.; Choi, Y.; Jang, E.; Lee, H.; Kang, B.; Kim, E.; Haam, S.; Suh, J.-S.; Chung, S.J.; et al. Chitosan-based intelligent theragnosis nanocomposites enable $\mathrm{pH}$-sensitive drug release with MR-guided imaging for cancer therapy. Nanoscale Res. Lett. 2013, 8, 467-478. [CrossRef] [PubMed]

22. Lim, E.-K.; Yang, J.; Suh, J.-S.; Huh, Y.-M.; Haam, S. Self-labeled magneto nanoprobes using tri-aminated polysorbate 80 for detection of human mesenchymal stem cells. J. Mater. Chem. 2009, 19, 8958-8963. [CrossRef] 
23. Ahmed, F.; Discher, D.E. Self-porating polymersomes of PEG-PLA and PEG-PCL: Hydrolysis-triggered controlled release vesicles. J. Control. Release 2004, 96, 37-53. [CrossRef] [PubMed]

24. Chen, H.; He, S. PLA-PEG coated multifunctional imaging probe for targeted drug delivery. Mol. Pharm. 2015, 12, 1885-1892. [CrossRef] [PubMed]

25. Chen, J.; Tian, B.; Yin, X.; Zhang, Y.; Hu, D.; Hu, Z.; Liu, M.; Pan, Y.; Zhao, J.; Li, H.; et al. Preparation, characterization and transfection efficiency of cationic PEGylated PLA nanoparticles as gene delivery systems. J. Biotechnol. 2007, 130, 107-113. [CrossRef] [PubMed]

26. Choi, J.S.; MacKay, J.A.; Francis, C.; Szoka, J. Low-pH-sensitive PEG-stabilized plasmid-lipid nanoparticles: Preparation and characterization. Bioconj. Chem. 2003, 14, 420-429. [CrossRef] [PubMed]

27. Ghasemi, R.; Abdollahi, M.; Emamgholi Zadeh, E.; Khodabakhshi, K.; Badeli, A.; Bagheri, H.; Hosseinkhani, S. mPEG-PLA and PLA-PEG-PLA nanoparticles as new carriers for delivery of recombinant human Growth Hormone (rhGH). Sci. Rep. 2018, 8, 9854. [CrossRef] [PubMed]

28. Hosseinkhani, H.; Tabata, Y. PEGylation enhances tumor targeting of plasmid DNA by an artificial cationized protein with repeated RGD sequences, Pronectin. J. Control. Release 2004, 97, 157-171. [CrossRef] [PubMed]

29. Hosseinkhani, H.; Tabata, Y. Ultrasound enhances in vivo tumor expression of plasmid DNA by PEG-introduced cationized dextran. J. Control. Release 2005, 108, 540-556. [CrossRef] [PubMed]

30. Kim, J.Y.; Kim, J.K.; Park, J.S.; Byun, Y.; Kim, C.K. The use of PEGylated liposomes to prolong circulation lifetimes of tissue plasminogen activator. Biomaterials 2009, 30, 5751-5756. [CrossRef] [PubMed]

31. Lim, D.W.; Park, T.G. Stereocomplex formation between enantiomeric PLA-PEG-PLA triblock copolymers. J. Appl. Polym. Sci. 2000, 75, 1615-1623. [CrossRef]

32. Park, T.G.; Yoo, H.S. Dexamethasone nano-aggregates composed of PEG-PLA-PEG triblock copolymers for anti-proliferation of smooth muscle cells. Int. J. Pharm. 2006, 326, 169-173. [CrossRef] [PubMed]

33. Ren, J.; Hong, H.-Y.; Ren, T.-B.; Teng, X.-R. Preparation and characterization of magnetic PLA-PEG composite particles. Mater. Lett. 2005, 59, 2655-2658. [CrossRef]

34. Tobío, M.; Sa'nchez, A.; Vila, A.; Soriano, I.; Evora, C.; Vila-Jato, J.L.; Alonso, M.J. The role of PEG on the stability in digestive fluids and in vivo fate of PEG-PLA nanoparticles following oral administration. Colloids Surf. B 2000, 18, 315-323. [CrossRef]

35. Venkatraman, S.S.; Jie, P.; Min, F.; Freddy, B.Y.; Leong-Huat, G. Micelle-like nanoparticles of PLA-PEG-PLA triblock copolymer as chemotherapeutic carrier. Int. J. Pharm. 2005, 298, 219-232. [CrossRef] [PubMed]

36. Vila, A.; Gill, H.; McCallion, O.; Alonso, M.J. Transport of PLA-PEG particles across the nasal mucosa: Effect of particle size and PEG coating density. J. Control. Release 2004, 98, 231-244. [CrossRef] [PubMed]

37. Xiao, R.Z.; Zeng, Z.W.; Zhou, G.L.; Wang, J.J.; Li, F.Z.; Wang, A.M. Recent advances in PEG-PLA block copolymer nanoparticles. Int. J. Nanomed. 2010, 5, 1057-1065.

38. Xiong, F.; Hu, K.; Yu, H.; Zhou, L.; Song, L.; Zhang, Y.; Shan, X.; Liu, J.; Gu, N. A functional iron oxide nanoparticles modified with PLA-PEG-DG as tumor-targeted MRI contrast agent. Pharm. Res. 2017, 34, 1683-1692. [CrossRef] [PubMed]

39. Yang, J.; Lee, T.-I.; Lee, J.; Lim, E.-K.; Hyung, W.; Lee, C.-H.; Song, Y.J.; Suh, J.-S.; Yoon, H.-G.; Huh, Y.-M.; et al. Synthesis of ultrasensitive magnetic resonance contrast agents for cancer imaging using PEG-fatty acid. Chem. Mater. 2007, 19, 3870-3876. [CrossRef]

40. Lim, E.K.; Haam, S.; Lee, K.; Huh, Y.M. Design and synthesis of biofunctionalized metallic/magnetic nanomaterials. Methods Mol. Biol. 2011, 751, 583-595. [PubMed]

41. Nikolic, L.; Ristic, I.; Adnadjevic, B.; Nikolic, V.; Jovanovic, J.; Stankovic, M. Novel microwave-assisted synthesis of poly(D,L-lactide): The influence of monomer/initiator molar ratio on the product properties. Sensors 2010, 10, 5063-5073. [CrossRef] [PubMed]

42. Wei, Q.; Li, T.; Wang, G.; Li, H.; Qian, Z.; Yang, M. $\mathrm{Fe}_{3} \mathrm{O}_{4}$ nanoparticles-loaded PEG-PLA polymeric vesicles as labels for ultrasensitive immunosensors. Biomaterials 2010, 31, 7332-7339. [CrossRef] [PubMed]

43. Jun, Y.-W.; Huh, Y.-M.; Choi, J.-S.; Lee, J.-H.; Song, H.-T.; Yoon, S.; Kim, K.-S.; Shin, J.-S.; Suh, J.-S.; Cheon, J. Nanoscale size effect of magnetic nanocrystals and their utilization for cancer diagnosis via magnetic resonance imaging. J. Am. Chem. Soc. 2005, 127, 5732-5733. [CrossRef] [PubMed]

44. Qiu, P.; Jensen, C.; Charity, N.; Towner, R.; Mao, C. Oil phase evaporation-induced self-assembly of hydrophobic nanoparticles into spherical clusters with controlled surface chemistry in an oil-in-water dispersion and comparison of behaviors of individual and clustered iron oxide nanoparticles. J. Am. Chem. Soc. 2010, 132, 17724-17732. [CrossRef] [PubMed] 
45. Lim, E.K.; Yang, J.; Suh, J.S.; Huh, Y.M.; Haam, S. Synthesis of aminated polysorbate 80 for polyplex-mediated gene transfection. Biotechnol. Prog. 2010, 26, 1528-1533. [CrossRef] [PubMed]

46. Azam, M.R.; Tan, I.M.; Ismail, L.; Mushtaq, M.; Nadeem, M.; Sagir, M. Static adsorption of anionic surfactant onto crushed Berea sandstone. J. Petrol. Explor. Prod. Technol. 2013, 3, 195-201. [CrossRef]

47. Lim, E.K.; Kim, T.; Paik, S.; Haam, S.; Huh, Y.M.; Lee, K. Nanomaterials for theranostics: Recent advances and future challenges. Chem. Rev. 2015, 115, 327-394. [CrossRef] [PubMed]

48. Phan, V.N.; Lim, E.-K.; Kim, T.; Kim, M.; Choi, Y.; Kim, B.; Lee, M.; Oh, A.; Jin, J.; Chae, Y.; et al. A highly crystalline manganese-doped iron oxide nanocontainer with predesigned void volume and shape for theranostic applications. Adv. Mater. 2013, 25, 3202-3208. [CrossRef] [PubMed]

49. Danaei, M.; Dehghankhold, M.; Atae, S.; Hasanzadeh Davarani, F.; Javanmard, R.; Dokhani, A.; Khorasani, S.; Mozafari, M.R. Impact of particle size and polydispersity index on the clinical applications of lipidic nanocarrier systems. Pharmaceutics 2018, 10, 57. [CrossRef] [PubMed]

50. Li, L.; Jiang, W.; Luo, K.; Song, H.; Lan, F.; Wum, Y.; Gu, Z. Superparamagnetic iron oxide nanoparticles as MRI contrast agents for non-invasive stem cell labeling and tracking. Theranostics 2013, 3, 595-615. [CrossRef] [PubMed]

(C) 2019 by the authors. Licensee MDPI, Basel, Switzerland. This article is an open access article distributed under the terms and conditions of the Creative Commons Attribution (CC BY) license (http://creativecommons.org/licenses/by/4.0/). 